\title{
High Adsorption Performance of Methyl Blue from Aqueous Solution Using Hyper- branched Polyethyleneimine Grafted MWCNTs as an Adsorbent
}

\author{
Jie Song ${ }^{1}$, Yulei Wang ${ }^{2}$ and Jun Qiu ${ }^{1,2 *}$
}

In order to explore greater potential of carbon nanotubes(CNTs) in removal of hazardous chemicals in waste water, short multiwalled carbon nanotubes(MWCNTs) were chemically grafted by polyethylenimine (PEI) with a high density of amines in this study. The characteristics results of TG, Raman and XPS show that PEI was successfully grafted onto the surface of MWCNTs for the adsorption of a novel anionic dye methyl blue (MB) under laboratory conditions. The new MWCNTs-PEI adsorbent contributes to an enhancement of the adsorption capacity in $\mathrm{MB}$ removal. The maximum adsorption capacity for MB is estimated to be $418 \mathrm{mg} / \mathrm{g}$ at $35^{\circ} \mathrm{C}$. The MWCNTs-PEI has a fast adsorption rate for $\mathrm{MB}$ in the first $5 \mathrm{~min}$ and high adsorption capacity. The adsorption of MB onto CNTs-PEI is found to be dependent on pH, initial concentration and temperature. It's found that equilibrium data for MB adsorption is fitted well by Langmuir isotherm model. The adsorption kinetics of MB is found to follow a pseudo-second-order kinetic model. The CNTs-PEI removal efficiency remains above $85 \%$ during the three cycles of the adsorption-desorption process. The MWCNTs-PEI could serve as a promising adsorbent for MB removal in wastewater.

Keywords: Carbon nanotubes; Polyethylenimine; Methyl blue; Adsorption.

Received 14 November 2018, Accepted 23 December 2018

DOI: $10.30919 / \mathrm{esmm} 5 \mathrm{f} 193$

\section{Introduction}

Dyes can make the fiber and other materials coloured, including synthetic and natural dye, which has widely application in textile, coating, plastics, photoelectric communication, food packaging. But in recent years, water pollution has become a serious environmental problem humans facing with which could influence industry or industrial products. Among this, wastewater due to dyes, is difficult to remove using traditional biodegradation method, owing to high chromaticity, complex organic matters, complicated constitutes, difficulty of degradation, and so on. ${ }^{1,2}$ Therefore, the efficient removal of dye from colored effluents is of special interest and great importance. A variety of removal technologies, including adsorption, ${ }^{3,4,5}$ chemical coagulation, liquid membrane separation, electrolysis, biological treatments, oxidation and some other processes have been carried out to treat the dye-contaminating wastewater. ${ }^{6-11}$ Among these, adsorption technology is regarded as an effective and economical technology, due to low-cost, flexible, simple experimental instrument and operation, low sensitive to toxic substance. It is an important physical-chemical method and has a great significance in dealing with dye wastewater. Besides, in the adsorption process, it can not produce other toxics. Obviously, the key is the effective adsorbent of high adsorption capacity and efficiency. In the past years, we have developed many adsorbents, such as active carbon, silica gel, activated alumina, molecular sieve in succession. ${ }^{12-15}$ But they all have different disadvantages, for example, low adsorption

\footnotetext{
${ }^{11}$ School of Materials Science and Engineering, Tongji University

Key Laboratory of Advanced Civil Engineering Materials of Education of Ministry, Shanghai 2018040,China

*E-mail: qiujun@tongji.edu.cn
}

efficiency, adsorption capacity and low selectivity. Therefore, it is the future inevitable trend to develop high performance adsorbents. It is reported that lignin grafted N,N'-methylene-bisacrylamide (LM) was copolymerized with acrylic acid (AA) to fabricate lignin based poly (acrylic acid) (LBPAA) nanocomposites, and organo-montmorillonite (OrgMMT) was uniformly dispersed in LBPAA by ultrasonic method. LBPAA/OrgMMT can be used as a water retention agent with salt tolerance and as an adsorbent for removing $\mathrm{Pb}^{2+}$ ions from industrial waste water. ${ }^{16}$ Fibrillar and particulate structure magnetic carbons (MCFs and MCPs) were prepared from the same precursor (polyacrylonitrile and $\left.\mathrm{Fe}\left(\mathrm{NO}_{3}\right)_{3} \cdot 9 \mathrm{H}_{2} \mathrm{O}\right)$ by using a different method, displaying a significant morphology dependence on wastewater treatment. ${ }^{17}$ Fluorine and nitrogen co-doped magnetic carbons (FN-MCs) were obtained through a facile pyrolysis-carbonization processes. FN-MCs were applied as adsorbents for the removal of chromium(VI) ions from aqueous solutions. ${ }^{18}$ A triple layered core-shell structured zero valence iron@-carbon@polyaniline (ZVI@C@PANI) nanocomposite was synthesized and was used to reduce the $\mathrm{Cr}(\mathrm{VI})$ in wastewater. The synthesized ZVI@C@PANI was demonstrated to have a great $\mathrm{Cr}(\mathrm{VI})$ removal performance with a fast rate and high capacity. ${ }^{19}$

Since first discovery in 1991 and quantity produced, CNTs have caused substantial attention and interest around the world, owing to its unique physical and chemical properties, and have aroused a great concern in verity of fields, such as high-strength carbon fiber materials, hydrogen-storage materials, catalyst carrier and so on. However, in aspect of environment protection, CNTs have an excellent base of adsorption because of its vast specific surface area and energy, abundant porous microstructure. In brief, CNTs have also been a promising adsorbent for removing various kinds of environmental pollutants, since they possess fibrous shape with high aspect ratio, large accessible external surface area, and well-developed mesopores. ${ }^{20-24}$ Therefore, 
CNTs might be ideal sorbents for the removal of dyes from water. Further appropriate surface modification, not only removing impurities including amorphous carbon, nano particles on its surface, but also introducing different kinds of functional groups, can enhance its adsorption performance. Hu Jun, Dadong Shao et al. synthesized the magnetic composite of $\beta$-cyclodextrin grafted onto MWCNTs/iron oxides (denoted as MWCNTs/iron oxides/CD) using the plasma-induced grafting technique and it was developed for the removal of inorganic and organic pollutants from aqueous solutions. the magnetic composite of MWCNTs/iron oxides/CD is a promising composite material for the preconcentration and separation of inorganic and organic pollutants from aqueous solutions in environmental pollution cleanup. ${ }^{25} \mathrm{Xu}$ Liheng, Jinye Li et al. constructed a novel CNT-based composite adsorbent by self-assembling CNTs onto solid microparticles. The CNT-based composites were in the shell-core structure, with CNTs entirely enwrapping the template particles. The adsorption characteristics of CNT-based composite adsorbents toward organic pollutants from aqueous systems were also explored. ${ }^{26}$ Farshid Homayoon, Hossein Faghihian et al. researched the magnetized adsorbent (MWCNTs $/ \mathrm{Fe}_{3} \mathrm{O}_{4}$ ) which was used for removal of $\mathrm{Hg}^{2+}$ from aqueous solutions. The adsorption capacity of $172.83 \mathrm{mg} / \mathrm{g}$ was obtained at $25^{\circ} \mathrm{C}$ and $\mathrm{pH}=3$ which was superior to the value obtained for initial MWCNTs, magnetized sample, and many previously reported values. ${ }^{27}$

As one of the common dyes, $\mathrm{MB}$, a novel anionic dye having three sulfonic acid groups $\left(-\mathrm{SO}_{3}\right)$, is widely used as the coloring agent and disinfecttor in rubbers, pharmaceuticals, pesticides, varnishes, and dyestuffs and so on. ${ }^{28}$ Traditional acid dye refers to the water- soluble dye containing acidic groups which exists in the form of sulfonic acid sodium salt in it. MB is a kind of typical strong-acid dyes. As shown in Fig. 1, every molecule contains three sulfonic acid group. We can see that the ratio of sulfonic acid group is high. Its dyeing mechanism is the combination of acidic groups and amino in fabric. Research on adsorption of MB has a lot of, such as organic bentonite, magnetic chitosan- graphene oxide nanocomposites, active carbon and barium phosphate. As a kind of widely used polymer, hyper- branched polyethyleneimine (PEI) is synthesized by the catalyzed ring-opening of aziridine (ethylene imine) which is a kind of viscous liquid with small viscosity, high solubility and good thermal stability . At the same time with highly branched structure its molecules are closely packed which form a three-dimensional structure. There exist a lot of groups containing different amounts of primary amine or secondary amine and tertiary amine which provides a number of sites available for modification. Synthetic route diagram is as shown in Fig. 2. Research shows that most of the secondary amine separate branched points, $3 \sim$ 3.5 of the nitrogen atoms appear at each branch along the fragment averagely. Therefore, PEI can play a role in cationic polyelectrolyte. For the attraction of anionic organic and inorganic materials, colloid and its surface, it can be used for adsorption of dye and other small molecules. The study found that the adsorption of highly branched polymer to small molecules is the physical function. The driving force of adsorption is the difference between polarity of core-shell, hydrogen bonding and electrostatic force. The hyper-branched PEI modified CNTs was rarely reported.

In this work, MWCNTs were chemically grafted by PEI with a high density of amines as the adsorbent of MB which is a kind of organic pollutant.MB could be adsorbed onto the surface of MWCNTs that have been grafted with PEI through strong electrostatic interactions arising from these amines.

\section{Materials and Methods}

\subsection{Materials}

Short multiwalled carbon nanotubes(MWCNTs) (OD $<8 \mathrm{~nm}$, ID, 2 5 $\mathrm{nm}$, length, $0.2 \sim 5 \mu \mathrm{m}$, purity $>95 \%$ ) were purchased from Chengdu Organic Chemical Co. Ltd., Chinese Academy of Sciences. Methyl blue (MB) $\left(\mathrm{C}_{37} \mathrm{H}_{27} \mathrm{~N}_{3} \mathrm{Na}_{2} \mathrm{O}_{9} \mathrm{~S}_{3}\right.$, molecular weight 799.81$)$, nitric acid(65\% $68 \%$ ), sulfuric acid(98 \%), analytically grade, purchased from Sinopharm chemical regent Co., Ltd. Hyper-branched polyethyleneimine(PEI) were supplied by Aldrich and Sigma Chemical. 3-(ethyliminomethyleneamino)-N,N -dimethyl-propan-1amine(EDC $\cdot \mathrm{HCl}), \mathrm{N}-\mathrm{Hy}$ droxysuccinimide (NHS) were purchased from Shanghai Medpep. Co., Ltd.

\subsection{Preparation of the adsorbent (MWCNTs-g-PEI) 2.2.1 Preparation of carboxylated MWCNTs}

The MWCNTs were suspended in a mixture of concentrated $\mathrm{H}_{2} \mathrm{SO}_{4}(98$ $\%) / \mathrm{HNO}_{3}(68 \%)(3: 1 \mathrm{in} \mathrm{v} / \mathrm{v})$, which produces carboxylic groups on the surfaces of the MWCNTs without resulting in large decreases of the lengths of the MWCNTs, under stirring using a high speed magnetic stirrer, equipped with a reflux condenser at $70{ }^{\circ} \mathrm{C}$ for $24 \mathrm{~h}$ and filtered through a nitrocellulose membrane (pore size: $0.45 \mathrm{um}$ ). The filtered matter was washed thoroughly by deionized water and this process was repeated several times until the filtrate was neutral. The obtained materials were dried in a vacuum oven at $100{ }^{\circ} \mathrm{C}$ for $24 \mathrm{~h}$.

\subsubsection{Preparation of aminated MWCNTs (MWCNTs-g-PEI)}

Fully aminated MWCNTs were prepared by the amination of the

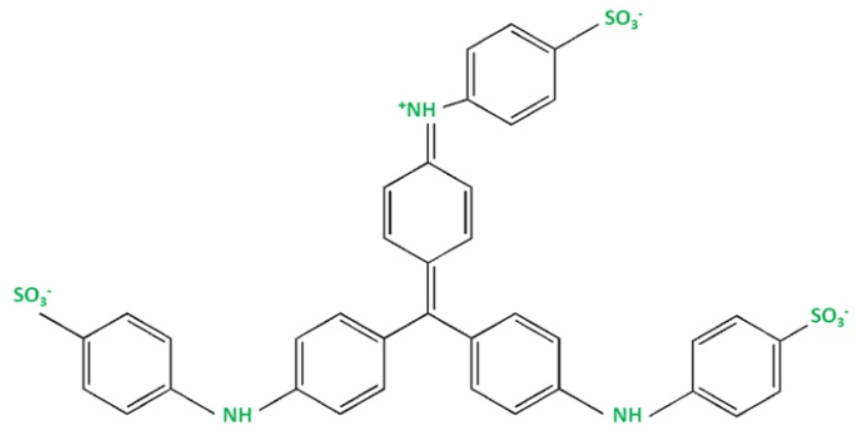

Fig. 1 The structural formula of MB.

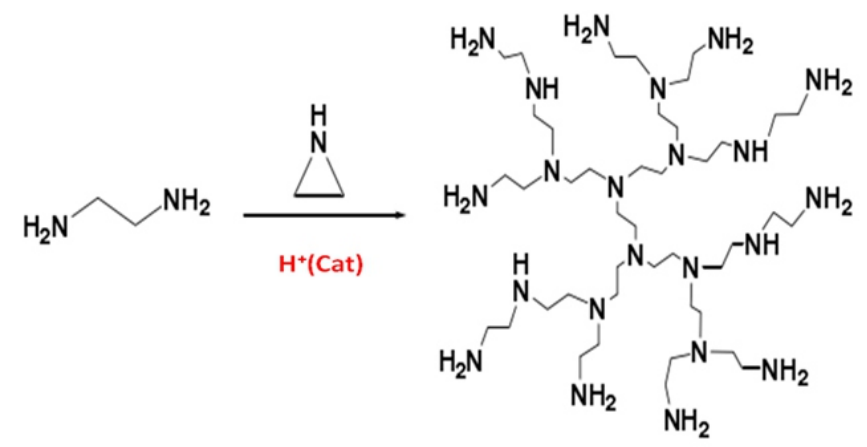

Fig. 2 Synthesis of hyper- branched polyethyleneimine. 
carboxylated MWCNTs through amide bond formation. ${ }^{29}$ The above 300 mg carboxylated MWCNTs were added in $20 \mathrm{~mL}$ deionized water by ultrasonic dispersion method, and then stirred on magnetic stirrer at room temperature. After $15 \mathrm{~min}, 300 \mathrm{mg} \mathrm{EDC} \cdot \mathrm{HCl}$ was added into the reaction and were stirred for $30 \mathrm{~min}$. Then, equal mass NHS was input. After 30min, PEI water aqueous solution $(1 \mathrm{~g}: 20 \mathrm{~mL})$ were put in the mixture. Finally, the whole reaction proceeded at room temperature for $48 \mathrm{~h}$. The suspension was filtered through a PP membrane (pore size: $450 \mathrm{~nm}$ ), washed with absolute ethyl alcohol for several times to remove the excess chemicals utill the filtrate was neutral. The remaining MWCNTs-g-PEI was dried in a vacuum oven at $100{ }^{\circ} \mathrm{C}$ for $24 \mathrm{~h}$.

\subsection{Characterization}

The surface chemical composition and bonding of the MWCNTs and its derivates were studied by X-ray photoelectron spectroscopy (XPS) using a VG-Microtech ESCA2000 equipped with a twin anode X-ray source and a hemispherical analyzer. Raman spectra were recorded with a Bruker Senterra Raman Microscope equipped with a $532 \mathrm{~nm}$ laser and a $10 \mathrm{f}$ old objective. The result was evaluated by extracting each single spectrum and the areas related with the $\mathrm{D}$ (disorder induced mode, centered around $1300 \mathrm{~cm}^{-1}$ ) and the $\mathrm{G}$ bands (graphite mode, around 1550 $\mathrm{cm}^{-1}$ ) have been estimated by two Gaussian fit. Thermo gravimetric analysis TGA curves were obtained by heating approximately $10 \mathrm{mg}$ of finely samples from room temperature to $800{ }^{\circ} \mathrm{C}$ at a constant heating rate of $10^{\circ} \mathrm{C} / \mathrm{min}$ in nitrogen condition under TA Instruments Q600 SDT thermal analyzer. The pore structures and specific surface areas of MWNTs were determined by adsorption of $\mathrm{N}_{2}$ at $77 \mathrm{~K}$ using an ASAP
2010 volumetric sorption analyzer. Specific surface areas and mesopore volumes of the sample were evaluated with the application of Brunauer-Emmett-Teller (BET) and Barrett-Joyner-

Halenda (BJH) equations, respectively.

\subsection{Adsorption experiment}

Batch adsorption experiments were performed using $50 \mathrm{ml}$ conical flask with addition of $10 \mathrm{mg}$ adsorbents and $50 \mathrm{ml}$ of a certain initial concentrations $\left(\mathrm{C}_{\mathrm{o}}\right)$. The conical flasks were all sealed and placed in a vapour-bathing constant temperature vibrator. In order to research the effects of temperature, the temperature was held in $288 \mathrm{k}, 298 \mathrm{k}$ and $308 \mathrm{k}$. At the end of equilibrium period, the suspensions were separated for later analysis of the remained solution concentration $\left(\mathrm{C}_{\mathrm{e}}\right)$. The amount of $\mathrm{MB}$ adsorption at equilibrium $\mathrm{q}_{\mathrm{e}}(\mathrm{mg} / \mathrm{g})$ was calculated from the following equation:

$$
\mathrm{q}_{\mathrm{e}}=\mathrm{V}\left(\mathrm{C}_{\mathrm{o}}-\mathrm{C}_{\mathrm{e}}\right) / \mathrm{W}
$$

where $\mathrm{C}_{\mathrm{o}}$ and $\mathrm{C}_{\mathrm{e}}(\mathrm{mg} / \mathrm{L})$ are the liquid-phase concentrations of dye at initial and equilibrium, respectively, $\mathrm{V}(\mathrm{L})$ the volume of the solution and $\mathrm{W}(\mathrm{g})$ is the mass of adsorbent used. The concentration of MB after and before adsorption was determined using Ultraviolet and Visible Spectrophotometer(UV-Vis) $(\lambda \max =598 \mathrm{~nm})$

The procedures of kinetic experiments were identical with those of equilibrium tests. The effect of contact time and initial concentration on the amount of MB adsorbed was investigated at 10,20,30 mg/L initial concentration. The amounts of MB adsorbed on CNTs at any time,
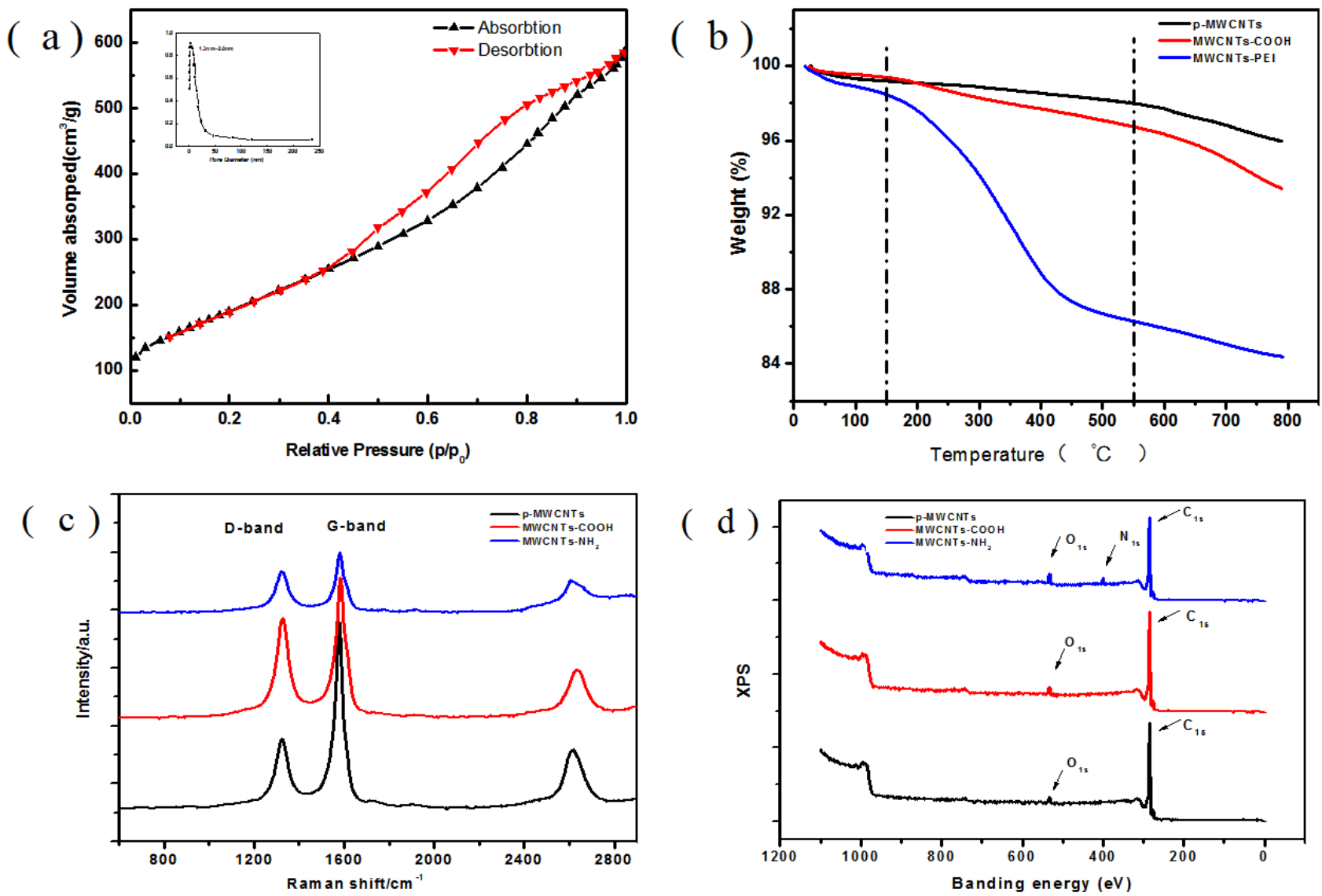

Fig. 3 (a) $\mathrm{N}_{2}$ adsorption-desorption curve and pore diameter distribution of p-MWCNTs, (b) TG curves of p-MWCNTs, MWCNTs-COOH and MWCNTs-PEI in $\mathrm{N}_{2}, 10^{\circ} \mathrm{C} / \mathrm{min}$ (c) Raman shift of p-MWCNTs, MWCNTs-COOH and MWCNTs-PEI (d) XPS spectra of p-MWCNTs, MWCNTs$\mathrm{COOH}$ and MWCNTs-PEI. 
$\mathrm{t}(\mathrm{min})$, were calculated from the concentrations in solutions before and after adsorption. At any times, the amount of MB adsorbed ( $\mathrm{mg} / \mathrm{g}$ ) onto CNTs was calculated from the mass balance equation as follows:

$$
\mathrm{q}_{\mathrm{t}}=\mathrm{V}\left(\mathrm{C}_{\mathrm{o}}-\mathrm{C}_{\mathrm{t}}\right) / \mathrm{W}
$$

where $\mathrm{q}_{\mathrm{t}}(\mathrm{mg} / \mathrm{g})$ is the amount of adsorbed dye on CNTs at any time, $\mathrm{t}$; $\mathrm{C}_{\mathrm{o}}$ and $\mathrm{C}_{\mathrm{t}}(\mathrm{mg} / \mathrm{L})$ are the initial and liquid-phase concentrations of $\mathrm{MB}$ at any time, $\mathrm{t}$, respectively; $\mathrm{V}(\mathrm{L})$ is the volume of $\mathrm{MB}$ solution, and $\mathrm{W}(\mathrm{g})$ is the mass of adsorbents used.

Furthermore, we also discussed the effect of the solution $\mathrm{pH}$, and cycle adsorption efficiency of the MWCNTs-PEI adsorbents.

\section{Results and Discussion}

\subsection{Characterization of adsorbents}

The BET surface area of the pristine MWCNTs(p-MWCNTs) which is calculated by the Barrett-Joyner-Halenda (BJH) method using the nitrogen desorption isotherm from Fig. 3(a). is $674 \mathrm{~m}^{2} / \mathrm{g}$, indicating that the MWCNTs adsorbents have a good potential of adsorption capacity. The insert figure is the typical pore size distribution, mainly in the $1.5 \sim 3 \mathrm{~nm}$. A hysteresis loop is clearly visible in the medium relative pressure $\left(\mathrm{P} / \mathrm{P}_{\mathrm{o}}=0.5 \sim 0.9\right)$ of the isotherm, which is associated with capillary condensation in mesopores. ${ }^{30}$ The scanning electron microscopy (SEM) images of p-MWCNTs are shown in Fig. 4. The image of pMWCNTs shows that the tube surfaces are clear and smooth. The single MWCNTs displays a smooth surface and the diameter of each tube is $5 \sim 8 \mathrm{~nm}$.

After the carboxylation and animation process, we have functionalized MWCNTs with hyperbranched PEI. The final product was characterized by different methods to confirm the chemical linkage of the organic molecule with the nanotubes.

The relative amount of PEI grafted onto the surface of MWCNTs was investigated by thermo gravimetric analysis (TGA) performed under nitrogen. Fig. 5 shows the weight change of the different MWCNTs derivatives, p-MWCNTs, MWCNTs-COOH, MWCNTs-PEI.

TGA trace of raw MWCNTs in the curve shows little weight loss ,which is about $1.8 \%$ below $600{ }^{\circ} \mathrm{C}$. The thermal degradation of MWCNTs is a multistage process. The first stage, up to a temperature of $150{ }^{\circ} \mathrm{C}$, a weight loss of approximately $1 \%$ is detected for the three MWCNTs derivative, which corresponds to the evaporation of the adsorbed water. We see that three curves have an obvious platform before $150{ }^{\circ} \mathrm{C}$. Thermal degradation in the range between the $150{ }^{\circ} \mathrm{C}$ and $550{ }^{\circ} \mathrm{C}$ is attributed to the decarboxylation of the carboxylic groups present on the MWCNTs walls and the elimination of hydroxyl functionalities. ${ }^{31,32}$ In the curve, the weight loss is about $3.7 \%$. Amino-functionalized MWCNTs has a steep weight loss after $150{ }^{\circ} \mathrm{C}$ until $550{ }^{\circ} \mathrm{C}$ (up to a new platform), mass loss $13 \%$, which is due to the fact that the additional organic functional groups are decomposed before the onset of MWCNTs' weight loss, which suggests that the surface of MWCNTs possess about $11 \%$ of PEI.

Raman spectroscopy is a very useful tool in analyzing the graphite degree of carbon-based materials. Fig. 3(c). illustrates the Raman spectra of p-MWCNTs, MWCNTs-COOH and MWCNTs-PEI sample excited with the $515 \mathrm{~nm}$ laser line, showing different crystalline structures. Each of them consists of two characteristic bands, namely the D-band at $\sim 1324 \mathrm{~cm}^{-1}$, the G-band at $1580 \mathrm{~cm}^{-1}$. The D-band is a disorder induced feature arising from double resonance Raman scattering process from a non-zero-center phonon mode. ${ }^{33}$ The D-band is usually attributed to the presence of amorphous or disordered carbon in the CNTs

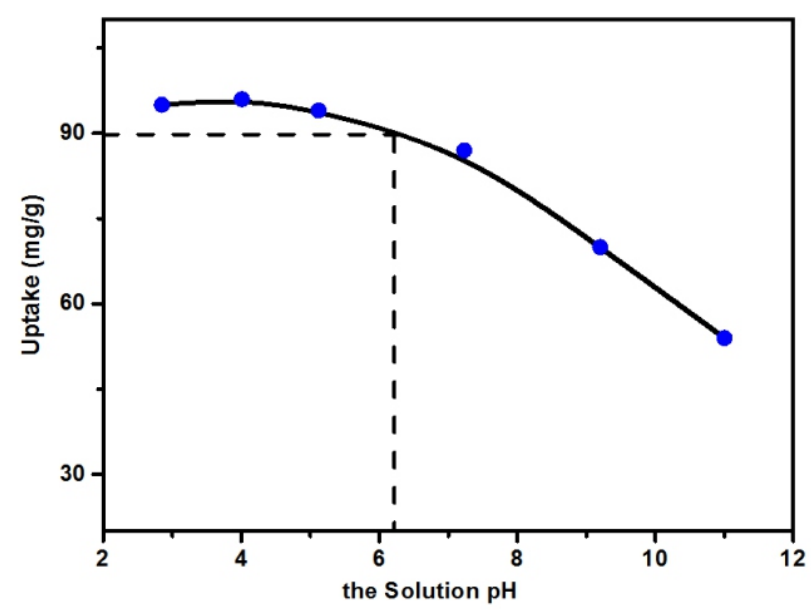

Fig. 5 Effect of solution $\mathrm{pH}$ on the adsorption of $\mathrm{MB}$ onto the MWCNTs-PEI(initial concentration: 20 mg/L, $298 \mathrm{~K}$ ).

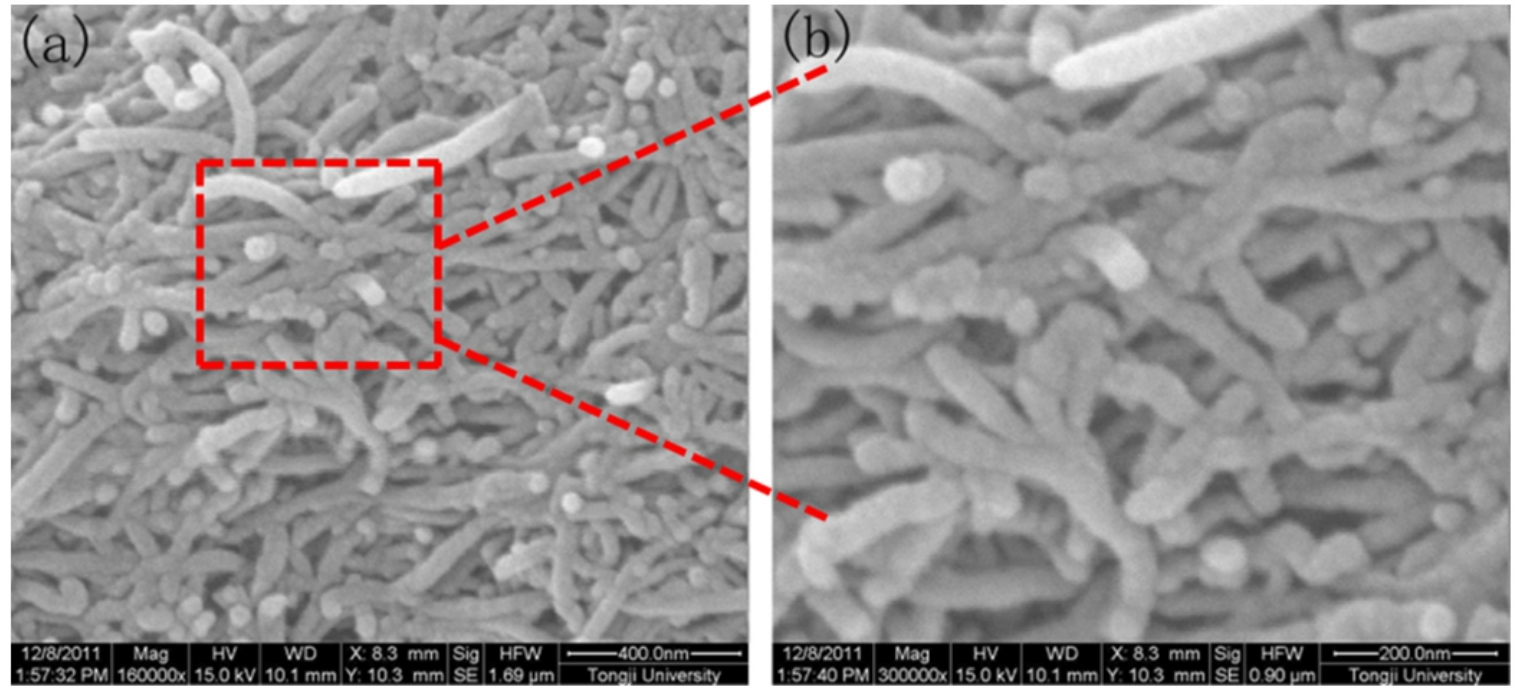

Fig. 4 SEM image of p-MWCNTs(a) and (b) 
samples. The carbon structural disorder is due to the finite or nanosized graphitic planes and other forms of carbon, such as rings along with defects on the nanotube walls, vacancies, heptagon-pentagon pairs, kinks and heteroatoms. It is important to mention that no systematic study has yet been carried out to differentiate the various contributions to the D band intensity. The G-band originates from in-plane tangential stretching of the carbon-carbon bonds in grapheme sheets. It is known that the intensity ratio of the intensities of the $D$ and $G$ peaks $\left(I_{D} / I_{G}\right)$ gives useful information on the graphite degree or the lattice distortion of carbon-based materials. ${ }^{34}$ The $\mathrm{I}_{\mathrm{D}} / \mathrm{I}_{\mathrm{G}}$ ratios have the following order: $\mathrm{p}$ MWCNTs (1.30) > MWCNTs-PEI (0.92) > MWCNTs-COOH (0.85) and $I_{D} / I_{G}$ ratio of MWCNTs-PEI is close to $I_{D} / I_{G}$ ratio of MWCNTs$\mathrm{COOH}$. It can be known that amination process would not change the structure of the CNT-COOH.

XPS analysis was also applied to determine the chemical species introduced by modification. Fig. 3(d). shows XPS spectra of (a) pMWCNTs, (b) MWCNTs-COOH and (c) MWCNTs-PEI. The peaks at 286.8, 401.8 and $534.2 \mathrm{eV}$ are attributed to $\mathrm{C}, \mathrm{N}$ and $\mathrm{O}$, respectively. The content of elements on surface of MWCNTs was calculated by the area of each element (as shown in Table 2). In the raw CNTs XPS spectra, it can be seen that the main element on the surface of CNTs is carbon, about $96.44 \%$ and the minute quantity is oxygen. After treated by mixed acid, the content of oxygen element increased to $4.45 \%$, which says that a certain amount of oxygen-containing functional groups were introduced while the content of nitrogen is still rare. Until PEI was grafted onto MWCNTs-COOH, we can see that the content of nitrogen was $3.49 \%$, confirming that PEI was successfully grafted and finding an agreement with the TG results. As shown in Table 1 , the $\mathrm{I}_{\mathrm{D}} / \mathrm{I}_{\mathrm{G}}$ ratios almost remain the same, finding in agreement with XPS analysis. That is, animation process is only the exchange of the functional groups on the CNTs surface.

\subsection{Effect of pH value on adsorption}

The solution $\mathrm{pH}$ can affect the surface charge of the adsorbent, the degree of ionization of the different pollutants, the dissociation of functional groups on the active sites of the adsorbent as well as the structure of the dye molecule. So $\mathrm{pH}$ value of the solution is an important parameter during the dye adsorption process. Fig. 5 shows the effect of initial $\mathrm{pH}$ ranging from $2 \sim 11$ on MB adsorption of MWCNTsPEI. It can be seen that, when the solution $\mathrm{pH}$ was below 6.2 , the adsorption uptake was remain a relatively high value. But when the solution $\mathrm{pH}$ is above 6.2, the adsorption capacity of MWCNTs-PEI adsorbents decreases significantly with increasing $\mathrm{pH}$ of the solutions. Therefore, the optimum $\mathrm{pH}$ range for $\mathrm{MB}$ adsorption onto the adsorbent was $6 \sim 7$. The adsorption mechanism could be explained by the fact that the ionic interactions of the colored dye with the amino groups of the adsorbent. In aqueous solution, the acid dyes are first dissolved and the sulfonate groups of acid aye $\left(\mathrm{D}-\mathrm{SO}_{3} \mathrm{Na}\right)$ dissociate and are converted to anionic dye ions.

$$
\mathrm{D}-\mathrm{SO}_{3} \mathrm{Na} \rightarrow \mathrm{D}-\mathrm{SO}_{3}^{-}+\mathrm{Na}^{+}
$$

Also, in the presence of $\mathrm{H}+$, the amino groups of the adsorbents (MWCNTs-PEI) became protonated,

$$
\mathrm{R}-\mathrm{NH}_{2}+\mathrm{H}^{+} \leftrightarrow \mathrm{R}^{-\mathrm{NH}_{3}^{+}}
$$

The adsorption process then proceeds due to the elatiectrostic attraction between these two oppositely charged ions,

$$
\mathrm{R}-\mathrm{NH}_{3}^{+}+\mathrm{D}-\mathrm{SO}_{3}^{-} \leftrightarrow \mathrm{R}-\mathrm{NH}_{3}^{+} \ldots . . \mathrm{SO}_{3}-\mathrm{D}
$$

However, at high $\mathrm{pH}$, the number of protonated $-\mathrm{NH}_{2}$ groups would decrease and more $\mathrm{OH}$ ions can be available to compete with the anionic sulfonic groups, therefore the adsorption capacity for the acid dyes decreases at high $\mathrm{pH}$ value.

\subsection{Effect of original concentration and contact time}

Fig. 6 shows the effect of contact time and initial concentration (10 $\mathrm{mg} / \mathrm{L}, 20 \mathrm{mg} / \mathrm{L}, 30 \mathrm{mg} / \mathrm{L}$, respectively) on the adsorption capacity of MB by the MWCNTs-PEI. It can be seen that the adsorption process is divided into three stages and the kinetics of MB uptake is very fast in the first $5 \mathrm{~min}$, followed by a slightly slower rate from $5 \mathrm{~min}$ to $30 \mathrm{~min}$, gradually leading to an equilibrium condition after $30 \mathrm{~min}$, for all the

Table 1 Raman parameters of the p-MWCNTs, MWCNTs-COOH and MWCNTs-PEI.

\begin{tabular}{cccc}
\hline Specimen & $\mathrm{D}-$ band $/ \mathrm{cm}^{-1}$ & $\mathrm{G}-$ band $/ \mathrm{cm}^{-1}$ & $\mathrm{R}=\mathrm{I}_{\mathrm{D}} / \mathrm{I}_{\mathrm{G}}$ \\
\hline pristine MWCNTs & 1322 & 1579 & 1.30 \\
MWCNTs-COOH & 1326 & 1582 & 0.85 \\
MWCNTs-PEI & 1322 & 1580 & 0.92 \\
\hline
\end{tabular}

Table 2 Element content of p-MWCNTs, MWCNTs-COOH, MWCNTs-PEI.

\begin{tabular}{ccc}
\hline Sample & Element & Content (\%) \\
\hline Pristine MWCN Ts & $\mathrm{C}_{1 \mathrm{~S}}$ & 96.44 \\
& $\mathrm{O}_{1 \mathrm{~S}}$ & 3.42 \\
MWCNTs treated by HNO3 (24h) & $\mathrm{N}_{1 \mathrm{~S}}$ & 0.14 \\
& $\mathrm{C}_{1 \mathrm{~S}}$ & 95.40 \\
MWCNT-COOH(24h) grafted PEI & $\mathrm{O}_{1 \mathrm{~S}}$ & 4.45 \\
& $\mathrm{~N}_{1 \mathrm{~S}}$ & 0.16 \\
& $\mathrm{C}_{1 \mathrm{~S}}$ & 90.04 \\
& $\mathrm{O}_{1 \mathrm{~S}}$ & 6.47 \\
\hline
\end{tabular}


Table 3 Adsorption kinetic parameters of MB onto MWCNTs-PEI.

\begin{tabular}{|c|c|c|c|c|c|c|c|c|c|}
\hline \multirow{2}{*}{$\begin{array}{l}\mathrm{q}_{(\mathrm{e}, \text { exp })} \\
\mathrm{mg} / \mathrm{g}\end{array}$} & \multicolumn{3}{|c|}{ Pseudo-first-order kinetic model } & \multicolumn{3}{|c|}{ Pseudo-second -order kinetic model } & \multicolumn{3}{|c|}{ Intraparticle diffusion model } \\
\hline & $\mathrm{K}_{1}$ & $\mathrm{q}_{(\mathrm{e}, \mathrm{cal})}$ & $\mathrm{R}^{2}$ & $\mathrm{~K}_{2}$ & $\mathrm{q}_{(\mathrm{e}, \mathrm{cal})}$ & $\mathrm{R}^{2}$ & $\mathrm{~K}_{\mathrm{p}}$ & $\mathrm{C}$ & $\mathrm{R}^{2}$ \\
\hline 47.5 & 0.06374 & 20.275 & 0.9187 & 0.00639 & 51.0465 & 0.99999 & 3.4999 & 20.2887 & 0.7909 \\
\hline 96.4 & 0.06598 & 48.2092 & 0.9381 & 0.00286 & 99.7009 & 0.9966 & 7.3506 & 33.2732 & 0.8640 \\
\hline 132 & 0.04003 & 55.94 & 0.8602 & 0.00221 & 125.3133 & 0.9994 & 8.7031 & 48.6812 & 0.8139 \\
\hline
\end{tabular}

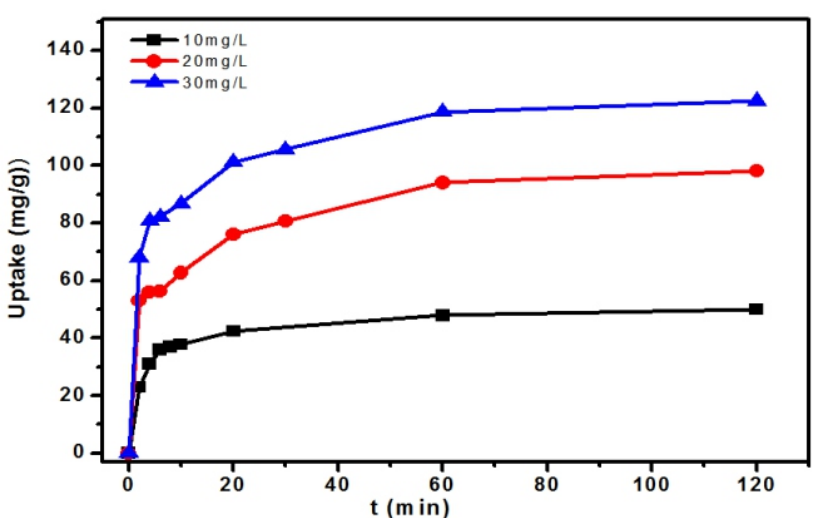

Fig. 6 Effect of Initial concentration and contact time (298k, MWCNTsPEI $=0.01 \mathrm{~g}$ ).

concentration studied. This result perhaps arrives because a large number of vacant surface sites are available for adsorption during the initial stage, and then, the remaining vacant surface sites are difficult to occupy because of the repulsive forces between the dyes molecules on the CNTs and the bulk phase. The MB uptake increases with increasing initial concentration. Apparently, adsorption is a passive process driven by the concentration gradient. The higher the initial concentration, the higher is the driving force, leading to a higher uptake.

Adsorption is a physicochemical process that involves mass transfer of a solute from liquid phase to the adsorbent's surface. In order to investigate the adsorption process of $\mathrm{MB}$ dyes on $\mathrm{CNTs}$, kinetic analysis was conducted using pseudo-first and second-order models and the intraparticle diffusion model. These models are most commonly used to describe the sorption of dyes as well as other pollutants (heavy metals) on solid sorbents. The Lagergren rate equation is one of the most widely used adsorption rate equations for the adsorption of solute from a liquid solution. The results of Fig. 6 are fitted using pseudo-first-and secondorder models and intraparticle diffusion model. Fig. 10 (a-c) displays the linear regressions. Table 3 presented the coefficients of the pseudofirst and second-order adsorption kinetic models and the intraparticle diffusion model. The pseudo-first-order kinetic model is expressed by the following equation:

$$
\ln \left(\mathrm{q}_{\mathrm{e}}-\mathrm{q}_{\mathrm{t}}\right)=\ln \mathrm{q}_{\mathrm{e}}-\frac{\mathrm{k} 1 \cdot \mathrm{t}}{2.303}
$$

where $\mathrm{q}_{\mathrm{e}}$ and $\mathrm{q}_{\mathrm{t}}$ are the amount adsorbed in $\mathrm{mg} / \mathrm{g}$ at equilibrium, time ' $\mathrm{t}$ ' in minute, and $\mathrm{K}_{1}$ is the rate constant of adsorption $\left(\mathrm{min}^{-1}\right)$. The values of experimental $\mathrm{q}_{\mathrm{e}}$ do not agree with the calculated ones, obtained from the linear plots (Fig. 7 a), and the values of correlation coefficient $\left(R^{2}\right)$ are relatively low for most of the adsorption data (Table 3). This shows
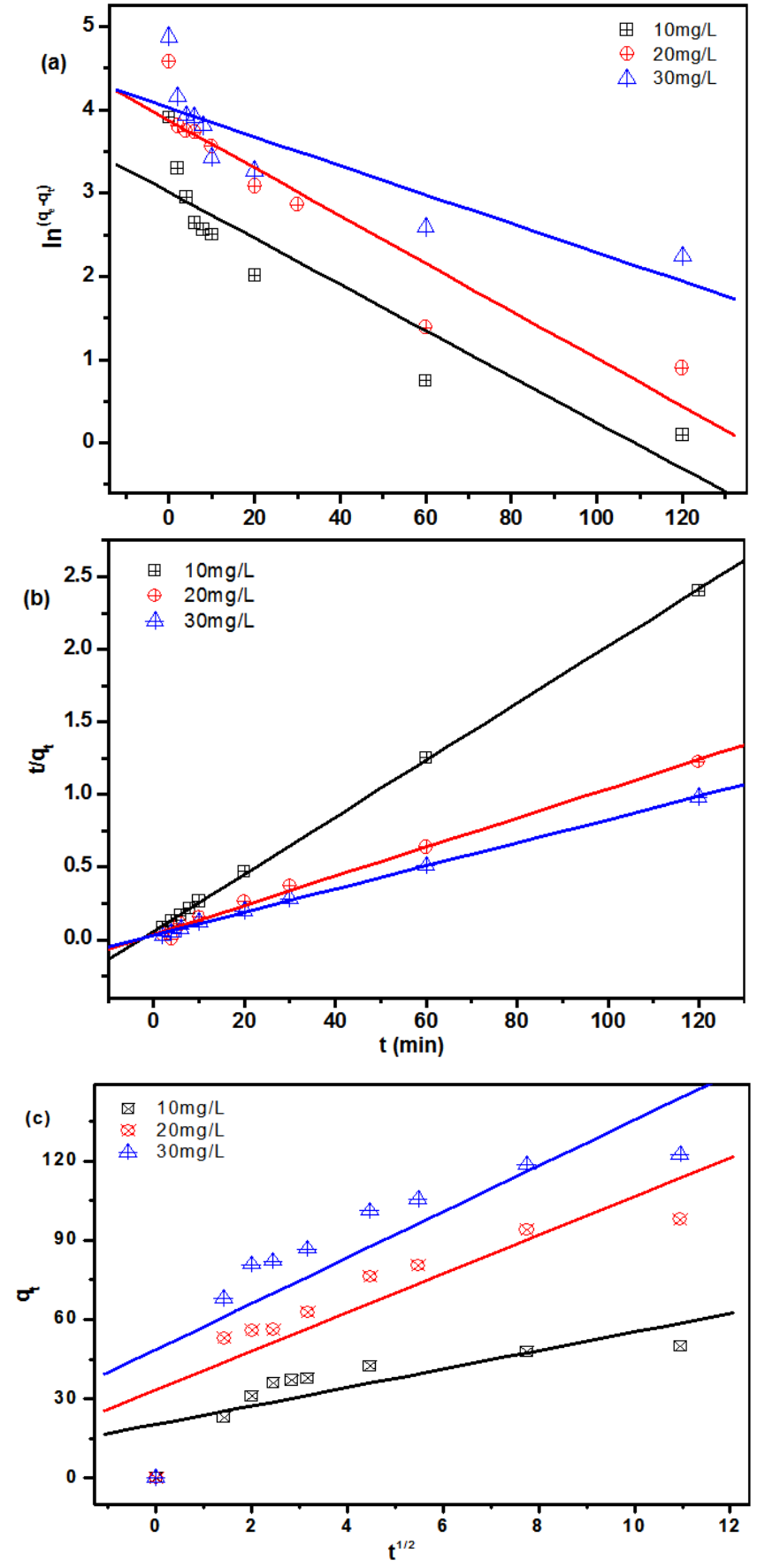

Fig. 7 Regressions of kinetic plots for the adsorption of $\mathrm{MB}$ at different initial concentration: (a) pseudo-first-order model, (b) pseudo-secondorder mode and (c) intraparticle diffusion model. 
that the adsorption process may not be the correct fit to the first-order rate equation. Another kinetic model is pseudo-second-order model, which is expressed by:

$$
\frac{\mathrm{t}}{\mathrm{q}_{\mathrm{t}}}=\frac{1}{\mathrm{k}_{2} \mathrm{q}_{\mathrm{e}}}+\frac{\mathrm{t}}{\mathrm{q}_{\mathrm{e}}}
$$

where $\mathrm{K}_{2}$ is the rate constant for the pseudo-second-order adsorption process. The linear plots of $\mathrm{t} / \mathrm{qt}$ versus $\mathrm{t}$ show good agreement between experimental and calculated qe values at different initial concentrations (Fig. 7 b). The correlation coefficient $\left(R^{2}\right)$ (Table 3) for the pseudosecond-order adsorption model has high value for adsorbent. These facts suggest that the pseudo-second-order adsorption mechanism in MWCNTs-PEI adsorbing MB is predominant.

Intraparticle diffusion model is described using the equation: ${ }^{36}$

$$
\mathrm{q}_{\mathrm{t}}=\mathrm{K}_{\mathrm{p}} \mathrm{t}^{0.5}+\mathrm{C}
$$

where $\mathrm{K}_{\mathrm{p}}$ is intraparticle diffusion constant $\left(\mathrm{mg} /\left(\mathrm{g} \cdot \mathrm{min}^{0.5}\right)\right)$. This can be obtained from plot of qt versus $\mathrm{t}^{0.5}$. The intercept that gives constant ' $\mathrm{C}$ ' indicates whether controlling step is intraparticle diffusion or not. If $\mathrm{C} \neq 0$, the adsorption mechanism is quite complex. If $\mathrm{C}=0$, adsorption kinetics is only controlled by intraparticle diffusion. In the study (Table 3 ), $\mathrm{C}$ is always a non-zero value revealing that the adsorption process is not controlled only by intraparticle diffusion but involves complex mechanism pathway, including the mainly chemisorption process of MB and mainly physisorption process of MWCNTs-PEI.

\subsection{Effect of original concentration and temperature}

Fig. 8 is the adsorption capacity contrast of the p-MWCNTs and MWCNTs-PEI at $25^{\circ} \mathrm{C}$. The result showed that the adsorption capacity of MWCNTs-PEI was dramatically increased to $418 \mathrm{mg} / \mathrm{g}$ compared with the adsorption capacity $212 \mathrm{mg} / \mathrm{g}$ of p-MWCNTs, confirming that PEI grafted onto p-MWCNTs can contributes to adsorption performance. Fig. 9 shows the effect of temperature and initial concentration on adsorption. As we can see, equilibrium adsorption capacity $\left(\mathrm{q}_{\mathrm{e}}\right)$ increased with the increasing of equilibrium MB concentrations at the range of experimental concentration. This is a result of the increase in the driving force from the concentration gradient. In the same conditions, if the concentration of $\mathrm{MB}$ in solution was higher, the active sites of CNTs were surrounded by much more $\mathrm{MB}$ ions, and the process of adsorption would carry out more sufficiently. Therefore, the values of qe increased with the increase of equilibrium $\mathrm{MB}$ concentrations. Also, the higher the experiment temperature, the higher equilibrium adsorption capacity the adsorbents had. This indicates that the adsorption of MB ions onto CNTs was endothermic in nature.

Study of equilibrium adsorption isotherm is fundamental in describing the interactive behavior between the adsorbate and the adsorbent and is important in designing an adsorption system. Fig. 10 shows the two widely used isotherm models, Langmuir (a) and Freundlich (b) isotherm model.

The most widely used Langmuir equation, which is valid for monolayer sorption onto a surface with a finite number of identical sites and is given by:

$$
\frac{\mathrm{C}_{\mathrm{e}}}{\mathrm{q}_{\mathrm{e}}}=\frac{\mathrm{C}_{\mathrm{e}}}{\mathrm{q}_{\mathrm{m}}}+\frac{1}{\mathrm{k}_{\mathrm{L}} \cdot \mathrm{q}_{\mathrm{m}}}
$$

where $\mathrm{C}_{\mathrm{e}}(\mathrm{mg} / \mathrm{L})$ is the equilibrium concentration, $\mathrm{q}_{\mathrm{e}}(\mathrm{mg} / \mathrm{g})$ is the adsorbed value of $\mathrm{MB}$ at equilibrium concentration, $\mathrm{q}_{\mathrm{m}}$ the maximum

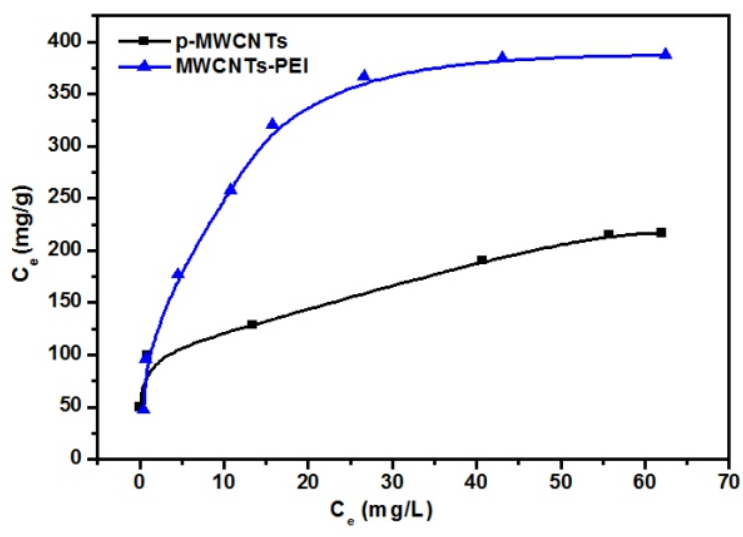

Fig. 8 Adsorption capacity of the p-MWCNTs and MWCNTs-PEI (298K).

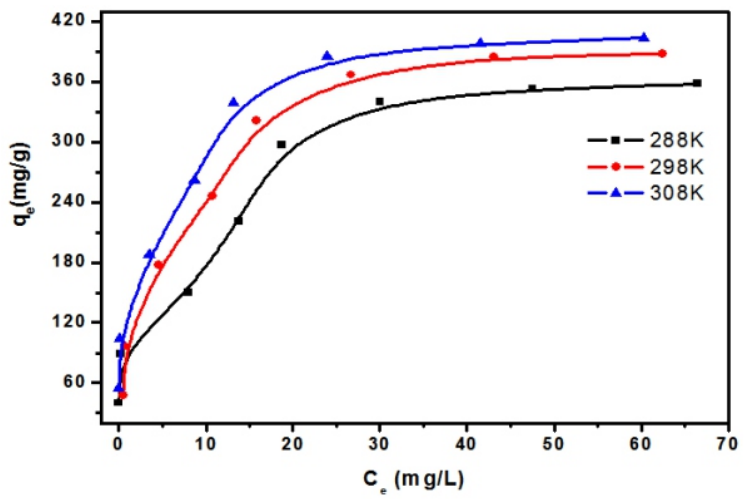

Fig. 9 Effect of temperature on adsorption.
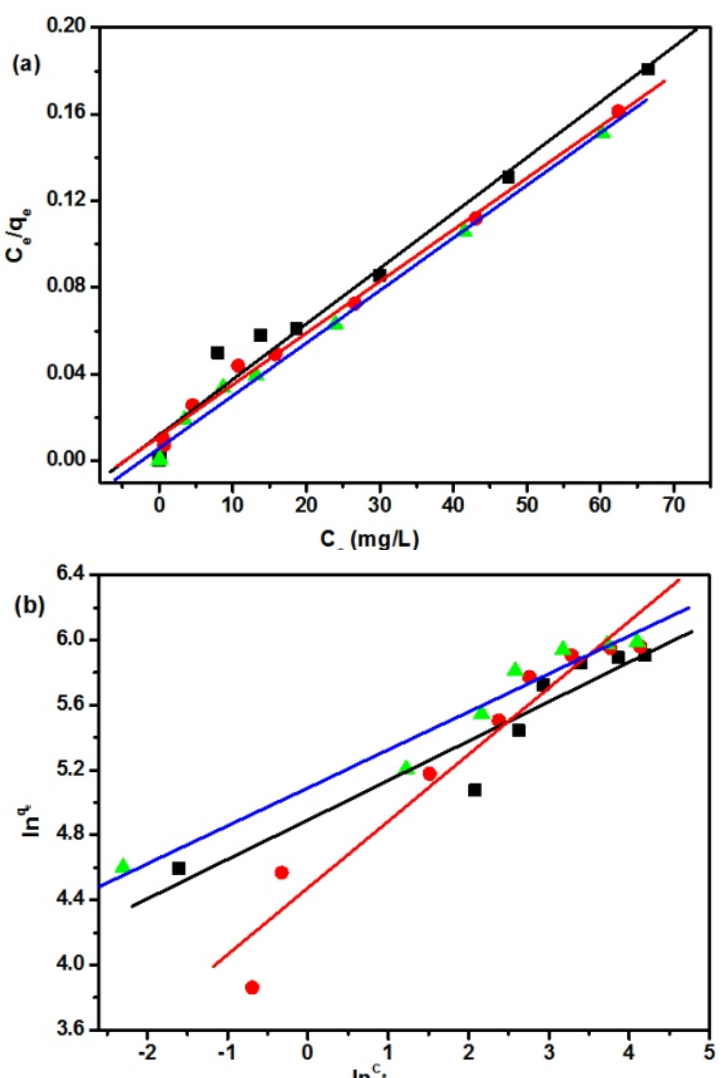

Fig. 10 Langmuir (a) and Freundlich (b) isotherms for MB adsorption onto MWCNTs-PEI at different temperatures. 
Table 4 Isotherm parameters for adsorption of MB by MWCNTs-PEI at different temperatures.

\begin{tabular}{ccccccc}
\hline $\mathrm{T}(\mathrm{k})$ & \multicolumn{3}{c}{ Langmuir model } & \multicolumn{3}{c}{ Frendulich model } \\
\hline & $\mathrm{K}_{\mathrm{L}}$ & $\mathrm{q}_{\mathrm{m}}$ & $\mathrm{R}^{2}$ & $\mathrm{~K}_{\mathrm{F}}$ & $\mathrm{n}$ & $\mathrm{R}^{2}$ \\
288 & 0.2144 & 390.63 & 0.9868 & 133.3957 & 4.412 & 0.9458 \\
298 & 0.2126 & 418.41 & 0.9974 & 87.8253 & 2.437 & 0.9686 \\
308 & 0.4123 & 413.22 & 0.9966 & 162.5686 & 4.276 & 0.9803 \\
\hline
\end{tabular}

adsorption capacity $(\mathrm{mg} / \mathrm{g})$, and $\mathrm{K}_{\mathrm{L}}$ is the Langmuir binding constant, which is related to the energy of adsorption. Plotting $\frac{\mathrm{C}_{\mathrm{e}}}{\mathrm{q}_{\mathrm{e}}}$ against $\mathrm{C}_{\mathrm{e}}$ gives a straight line with slope and intercept equal to $\frac{1}{\mathrm{q}_{\mathrm{m}}}$ and $\frac{1}{\mathrm{k}_{\mathrm{L}} \cdot \mathrm{q}_{\mathrm{m}}}$ respectively.

The value of $\mathrm{q}_{\mathrm{m}}$ obtained from Langmuir curves (Table 4) are mainly consistent with that experimentally obtained, indication that the adsorption process is mainly monolayer. The Freundlich isotherm model is an empirical relationship describing the adsorption of solutes from a liquid to a solid surface, and assumes that different sites with several adsorption energies are involved. The linear form of the Freundlich equation is:

$$
\ln \mathrm{q}_{\mathrm{e}}=\ln \mathrm{K}_{\mathrm{F}}+\frac{1}{\mathrm{n}} \cdot \ln \mathrm{C}_{\mathrm{e}}
$$

where $\mathrm{K}_{\mathrm{F}}$ is constant indicating sorption capacity $(\mathrm{mg} / \mathrm{g}) . \mathrm{K}_{\mathrm{F}}$ and $\mathrm{n}$ can be determined from linear plot of $\operatorname{lnq}_{\mathrm{e}}$ against $\operatorname{lnC}_{\mathrm{e}} \cdot \mathrm{n}$ gives an indication of how favorable the adsorption process. It is generally stated that values of $\mathrm{n}$ in the range 2-10 represent good, 1-2 moderately difficult, and less than 1 poor adsorption characteristics. The studied materials are good adsorbents for MB $(n>2)$. Fig. $10 \mathrm{~b}$ shows that the adsorption of $\mathrm{MB}$ also follows the Freundlich isotherm. Accordingly, Freundlich constants $\left(\mathrm{K}_{\mathrm{F}}\right.$ and $\left.\mathrm{n}\right)$ were calculated and listed in Table.4.

\subsection{Cycle adsorption efficiency of adsorbents MWCNTs-PEI}

The recovery of adsorbed material, as well as regeneration of adsorbents, is becoming important, and the recycling and regeneration abilities of the adsorbent are crucial for its practical application. Such adsorbent has both high adsorption capability and good desorption property which will reduce the overall cost for the adsorbent. So, we further developed the desorption experiments to evaluate the reusability of the MWCNTs-PEI. Desorption of MB from MWCNTs-PEI was demonstrated using a $0.1 \mathrm{M} \mathrm{NaOH}$ concentration in ethanol. The effect of four adsorption-desorption cycles was studied, and the results are shown in Fig. 11. It is shown that the uptake capacity of $\mathrm{MB}$ on MWCNTs-PEI decreased slowly with increasing cycle number, but in the three cycles, the adsorption efficiency remained $90 \%$. After the fourth regeneration cycle, the adsorption efficiency remained $78 \%$. Therefore, the experiment results confirmed that the MWCNTs-PEI adsorbent can be recycled for the following MB adsorption, and the MWCNTs-PEI can be reused for several times. This could be due to the fact that, in basic solution, the positively charged amino groups were deprotonated and the electrostatic interaction between $+\mathrm{NH}_{2}$ (basic groups) and $\mathrm{MB}$ molecules became much weaker. Therefore, the MWCNTs-PEI adsorbents can be reused for MB removal for three times at least under $90 \%$ of adsorption efficiency.

\section{Conclusion}

MWCNTs were functionalized by PEI with a high density of amines in

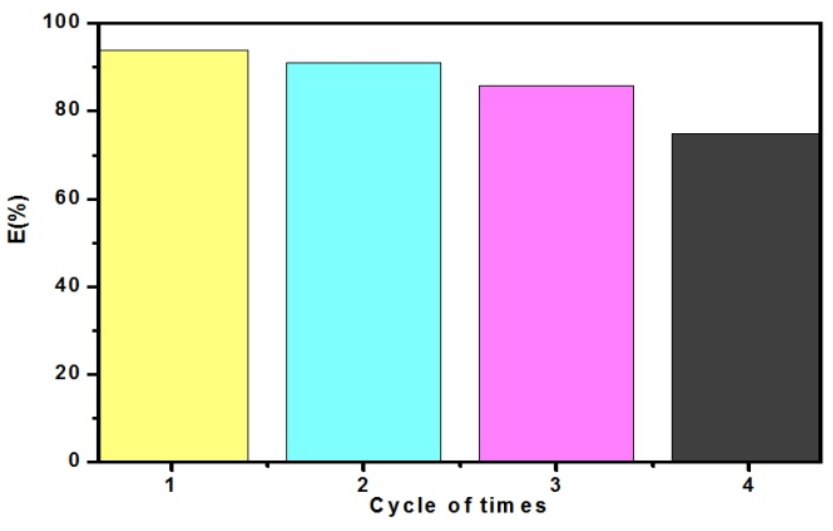

Fig. 11 Effect of recycling adsorbents on MB adsorption (initial concentration, $1000 \mathrm{mg} / \mathrm{L}$, adsorbents mass $0.1 \mathrm{~g}$; temperature, $298 \mathrm{~K}$ ).

this study, which was used as adsorbent for MB from aqueous solutions and has a higher adsorption capacity, a fast adsorption rate for MB in the first 5min due to the introduction of $+\mathrm{NH}_{2}$ compared with the pristine CNTs. The adsorption of MB on MWCNTs-PEI is dependent on $\mathrm{pH}$, temperature and initial concentration, indicating an ion exchange mechanism. The adsorption follows pseudo-second-order kinetics, and the equilibrium data are well fitted with the Langmuir isotherms. Furthermore, the MWCNTs-PEI loaded with MB could be desorbed in $0.1 \mathrm{M} \mathrm{NaOH}$ concentration in ethanol. The desorbed adsorbent could be reused at least for three times at least under $90 \%$ of adsorption efficiency.

\section{Acknowledgements}

This work was supported by Natural Science Foundation of China (51173133).

\section{Conflict of Interest}

We declare that we have no conflict of interest.

\section{Reference}

1. S. Li, Bioresource Technology, 2010, 101, 2197-2202.

2. N. Bao, Y. Li, Z. Wei, Guangbin. Yin and Junjian. Niu, J. Phys. Chem., 2010, C115, 5708-5719.

3. I. U. Emmanuel, O. A. Kayode, and A. D. Folasegun, J. Hazard. Mater., 2008, 157, 397-409.

4. J. Chen, W. Chen and D. Zhu, Environ. Sci. Te, 2008, 42, 7225-7230.

5. B. Coasne, C. A. Simionesco, F. Audonnet, G. Dosseh and E. G. Keith, Phys. Chem.Chem. Phys., 2010, 13, 3748-3757.

6. E. Gohary and K. A. Tawfi, Desalination, 2009, 249, 1159-164.

7. A. Dâas and O. Hamdaoui, J. Hazard. Mater, 2010, 178, 973-981.

8. L. Wang, J. Hazard. Mater, 2009, 171, 577-581.

9. E. N. Muftah, and A. M. Shaheen, J. Hazard. Mater., 2009, 164, 720-725. 
10. T. G. Helder, F. M. Bruno, A. Ribeiro, I. Moreira, M. 'arcio, S. Adri, L. Figueiredo and L. F. Joaquim, J. Hazard. Mater, 2008, 159, 420-426.

11. T. Wu,X. Cai, S. Tan, H. Li, J. Liu and W. Yang, Chem. Eng. J., 2010, 173, 144-149.

12. A. Demirbas, J. Hazard. Mater., 2009, 167, 1-9.

13. T. T. Wen, J. H. Kuo and C. H. Hsin, J. Hazard. Mater, 2009, 166, 635-641.

14. L. H. Ai, Y. Zhou and J. Jiang, Desalination, 2010, 266, 72-77.

15. L. H. Ai, Y. Zhou and R. Zhang, Synthetic Met., 2010, 160, $762-767$.

16. Jiangnan Huang, Yonghai Cao and Qian Shao, Polymer, 2017, 128, 12-23.

17. Jiangnan Huang, Yonghai Cao and Qian Shao, In. Eng. Chem. Res., 2017, 56, 10689-10701.

18. Jiangnan Huang, Yuhang Li and a Yonghai Cao, J. Mater. Chem. A, 2018, 5.

19. Kedong Gong, Qian Hu and Yangyi Xiao, J. Mater. Chem. A, 2018, 6, $11119-11128$

20. X. Ren, C. Chen, M. Nagatsu and X. Wang, Chem. Eng. J., 2011, 170, 395-410.

21. A. S. Tawfik, M. A. Gondal, Q. A. Drmosh, Z. H. Yamani, and A. A. Lyamani, Chem. Eng. J., 2011, 166, 407-412.

22. A. S. Tawfik and K. G. Vinod, J. Colloid Int. Sci., 2011, 362, 337-344.

23. K. Gupta. Vinod, S. Agarwal and A. S. Tawfik, J. Hazard. Mater, 2011, 185,
$17-23$.

24. A. S. Tawfik, M. A. Gondal and Q. A. Drmosh, Nanotechnology, 2010,21,495705.

25. J. Hu, D. Shao and C. Chen, J. Phys. Chem. B, 2010, 114, 6779-6785.

26. L. Xu, J. Li and M. Zhang, Ind. Eng. Chem. Res., 2015, 54, 2379-2384.

27. F. Homayoon, F. A. Hossein and F. Torki, Environ. Sci. Pollut. R., 2017, 24, 11764-11778.

28. T. Wu, X. Cai, S. Tan, H. Li, J. Liu and W. Yang, Chem. Eng. J., 2011, 173, 144-149.

29. Y. Kong, J. Yuan and J. Qiu, Phys. B, 2451, 407, 2451-2457.

30. Q Yang, P. Hou, S. Bai, M. Wang and H. Cheng, Chem. Phys. Lett., 2001,345,18-24.

31. M. Sendova, E. Flahaut and B. DeBono, J. Appl. Phis., 2005, 98, 104304.

32. T. Chen, Y. Lin, W. Chen and J. Wei, Powder Technol., 2009,192,16-22.

33. M. Tang, H. Dou and K. Sun. Polym., 2006, 47, 728-734.

34. Y. Kong, J. Yuan, Z. Wang and J. Qiu, Polym.composite., 2012, 1613-1619.

35. L. Zhou, J. Jin and Z. Liu, J. Hazard. Mater, 2011, 185, 1045-1052.

36. G. K. Ramesha, A. K. Vijaya, H. B. Muralidhara and S. Sampath, J. Colloid Int. Sci., 2011, 361, 270-277. 